\title{
CFD Study on Impeller Effect on Mixing in Miniature Stirred Tank Reactor
}

\author{
Adnan Ghulam Mustafa ${ }^{1}$, Mohd Fadhil Majnis ${ }^{1,{ }^{*}}$, Nor Azyati Abdul Muttalib ${ }^{2}$ \\ 1 Department of Chemical and Petroleum Engineering, Faculty of Engineering, Technology \& Built Environment, UCSI University Kuala Lumpur, \\ Malaysia \\ 2 Department of Bioprocess Engineering, Faculty of Engineering, Universiti Teknologi Malaysia, Malaysia
}

ARTICLE INFO

\section{Article history:}

Received 22 August 2020

Received in revised form 21 October 2020

Accepted 24 October 2020

Available online 30 October 2020

\section{Keywords:}

ANSYS Fluent; computational fluid dynamics; multiple reference frame; turbulent mixing; two-phase mixing

\section{ABSTRACT}

Mixing of fluid can happen in existence or absence of impeller which will affect the mixing performance. The hydrodynamics behavior of fluid has a strong effect on the mixing. The design of mixing systems and operation using the agitated tanks is complicated because it is difficult to obtain accurate information for turbulence's impeller induced. Computational Fluid Dynamics can be used to provide a detailed comprehension of those systems. This paper describes the effect of various designs of impeller in miniature stirred tank reactor towards the mixing of the calcium alginate beads with the milk using Computational Fluid Dynamics (CFD) software, ANSYS Fluent 19.2. The four different type of impellers are edge beater, 5-turbine blade, t-shape, and paddle. The impeller was simulated at different speeds of $150 \mathrm{rpm}, 250 \mathrm{rpm}$, and $300 \mathrm{rpm}$. K-epsilon turbulence model was employed to simulate the flow distribution pattern of calcium alginate beads and the Multiple Reference Frame approach was used for the impeller rotation's simulation. The simulation results obtained have a good agreement with the experimental results in term of vortex formation. The simulation results obtained for contour plots were fitted well with the experimental results as well as with pattern of impeller flow which was also studied. As a result, an optimal design of the impeller that is able to produce good mixing can be achieved using CFD analysis. The results obtained after performing the simulation proved that edge beater blade outperformed the other impellers and took the least time to fully distribute the calcium alginate beads in the tank at $250 \mathrm{rpm}$ compared to 150 and 300 rpm. It can also be concluded that the edge beater blade is the best for the mixing of two-phase fluid and also produces mixed pattern flow. The obtained results from CFD can also be used to scale up the mixing process in larger systems.

\section{Introduction}

Various process industries such as chemicals, bio-chemicals, polymer, crystallization, mineral, food and pharmaceutical industries [1] use fluid mixing to mix a phase of the fluid system

\footnotetext{
*Corresponding author.

E-mail address: fadhil@ucsiuniversity.edu.my (Mohd Fadhil Majnis)
}

https://doi.org/10.37934/cfdl.12.10.1526 
(homogeneous mixing) or liquid with solid (heterogeneous mixing). Homogeneous mixing happens when the fluid is the same phase whereby heterogeneous mixing happens when the fluid is in different phase [2]. Regarding the widespread of these processes in industries, mixing of the fluid is done in various ways and in many kinds of equipment such as stirred vessels, rotor-stator mixers, and static mixers [3]. Stirred vessels among all the other mixers equipment are the most recorded common devices in mixing of fluid in the area of process application used [4].

In many industrial applications solid suspension can be find out in chemical industries, pharmaceuticals, catalytic mixing in petrochemical industries, mineral, and sterilization industries. It is dependent on the particle of solid size and density, the particles of solid may settle at the bottom of the vessel base if the density is greater than the density of the liquid $(\rho S>\rho L)$, or density of the liquid is great than the density of the solid, it float on the surface of the liquid $(\rho L>\rho s)[2,5-8]$. In order to attain a high mass and heat transfer, or reaction of chemical between the different phase (heterogeneous) such as solid and liquid phase, prevention of the settling of the solid particle to the bottom of the vessel base in the liquid phase need to be lifted from the bottom vessel to the top of the liquid surface to have good product quality and more yield of the product. Solid suspension can be classified into three Categorize: 1) Partial Suspension, 2) Complete Suspension and 3) Uniform Suspension [9]. Most industrial application want to achieve complete suspension of the solid particle which is attain by the higher speed of the impeller (Critical state) whereby no industry wants to have a non-uniform suspension of solid such as in crystallizer it will cause irregular shape and growth of the solid particle moreover for the uniform suspension which is obtained in much higher speed then the complete suspension condition.

The reason of mixing fluids two or more phases in stirred vessels is to decrease the dead zone [10], which is inhomogeneity, in order to accomplish a required process result. For instance, the decrease of heterogeneity in the liquid-solid system of the solid distribution [11]. This would increase the yield of the product without the raw material wasting. In CFD, modelling of mixing of numerous fluids in single-phase system in impeller vessel of various configuration and design has been broadly validated. However, since calcium alginate is transparent, result of the mixing of calcium alginate in the milk cannot be seen in the experiment [12-14] and shortcomings in the manufacturing of impeller which has led to the computational domain approach.

The result could have been more accurate by using a smaller mesh size which could have taken more computational time therefore a suitable mesh size was used to save time. Furthermore, no investigation was done for the area of multiple reference frame (MRF) which might had implications on the result. The importance of this simulation was to overcome the mass transfer limitations encountered during the mixing and to prevent the vortex formation which could affect the efficiency rate of the mixing which helps the calcium alginate bead to be fully distributed inside the reactor. In this study, four different type of impellers were used to find the effect on the mixing of two-phase system which is solid as calcium alginate beads and liquid as milk. Types of impeller studied in this research were T-shape, edge beater blade, paddle blade and 5-turbine blade and studied the effect of impeller on the flow pattern of the milk. Computational Fluid Dynamic (CFD) was used to simulate and investigate all these effects and the result obtained were compared with experimental result to investigate the validity of simulation result with the experimental results. Simulations were done using commercial software, ANSYS Fluent 19.2 solver and meshing was achieved by the hyper-mesh software. The k-epsilon $(\varepsilon)$ model was used to set up the turbulent flow process and the multiple reference frames (MRF) approach [15] used to model the impeller motion in a tank. 


\section{Methodology}

A preliminary study is the step of data collection for the data input of the different impeller modelling. Therefore, the data input for this study was obtained from the research work by Muttalib [16] on the distribution of calcium alginate beads in the miniature stirred tank reactor associated with complete experiment validation and the result of the different impeller at different speed and whether vortex was formed. Tank height was $2.8 \mathrm{~cm}$, diameter was $3.2 \mathrm{~cm}$. The distance from bottom of the tank to the impeller and diameter of each impeller is shown in Table 1 whereby $\mathrm{C}(\mathrm{cm})$ is the distance from the bottom of the tank; $D(\mathrm{~cm})$ is the diameter of the impeller; $W(\mathrm{~cm})$ is the width of the impeller.

$\begin{aligned} & \text { Table } 1 \\
& \text { Dimension of impellers }\end{aligned}$
\begin{tabular}{llll}
\hline Impeller Type & $\mathrm{C}(\mathrm{cm})$ & $\mathrm{D}(\mathrm{cm})$ & $\mathrm{W}(\mathrm{cm})$ \\
\hline T-shape & 0.4 & 1.8 & 0.5 \\
5-Blade Turbine & 0.1 & 1.8 & 0.8 \\
Paddle & 1.6 & 1.4 & 1.2 \\
Edge Beater blade & 0.1 & 1.9 & 2.1 \\
\hline
\end{tabular}

The computational domain, as a consequence of using multiple reference frame (MRF) methods, the MRF frame was chosen in such a dimension so that all the impeller have the same size and dimension of it and it is necessary to be divided into two regions, as shown in Figure 1. Inner domain containing all of the rotating elements (hub, blades and shaft), and the other containing the stationary parts (tank wall, base and other parts of shaft which is out of the inner domain) which is outer domain separated by three interfaces. MRF is chosen as it takes much less computational domain compared to the SG [17].

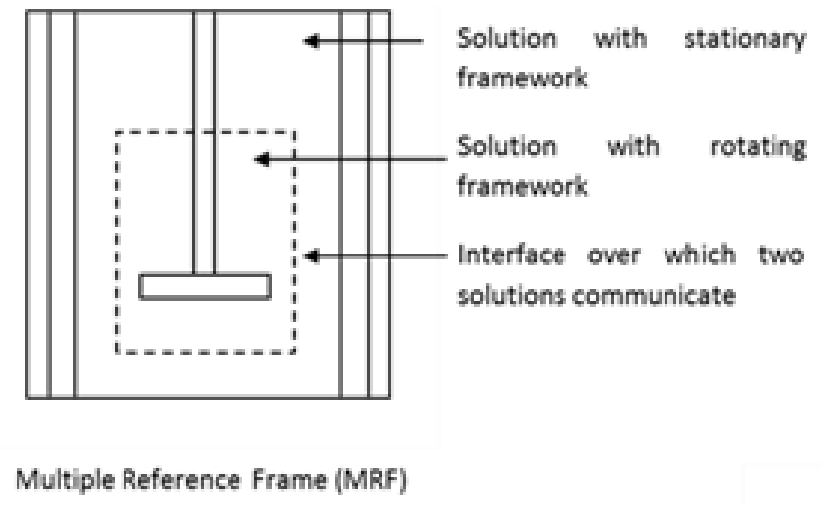

Fig. 1. Display show stationary and rotational zone

The design of each model was done using ANSYS 19.2 built-in software called Design-Modeler. After designing each part, Boolean (subtract section) was selected to make three section inner domain as MRF, impeller and outer domain the tank.

\subsection{Meshing}

The geometry of each design was imported to Hyper-mesh software to be meshed, the mesh size for this study for all the design was set to $0.1 \mathrm{~cm}$. later the file was imported to mesh mode to generate in the mesh file for ANSYS Fluent solver. 


\subsection{Setup (Ansys Fluent)}

After the mesh was generated and done naming on the boundaries in hyper mesh, it was then imported to ANSYS Workbench and imported into the solver, Fluent. The setup stage was divided into general, model, materials, cell zone conditions, boundary conditions and mesh interfaces. For this study, a pressure-based solver is chosen due to its suitability for this case whereby there are no density changes in the incompressible flow of milk. Then, the transient state was chosen instead of steady-state for this study because of the experimental work which conducted four different impeller to run for different time period to achieve maximum distribution of the calcium alginate. Reynold number were calculated using the Eq. (1) [18].

$R e_{i m p}=\frac{\rho \mathrm{N} D^{2}}{\mu}$

where the viscosity, $\mu$, density of milk, $\rho$ and radius of impeller, $D$. Turbulence modelling method of Computational Fluid Dynamics was used. The models used were $\mathrm{k}-\varepsilon$ mode. In the $k-\varepsilon$ model dispersed the turbulent kinetic energy $k$ and its rate of dissipation $\varepsilon$ are obtained from the transport equations. Multiphase model because of two phases of fluid (milk and calcium alginate) was chosen. There are two fluid streams in this study, Calcium Alginate beads (solid) and milk which was chosen as water and some of the properties for both the fluid were changed accordingly to the experimental work. The properties of air were initially built-in in the Fluent Database where it only requires selecting it from the Fluent database and apply it to the material panel and then the air properties were changed to calcium alginate bead as shown in Table 2.

\section{Table 2}

Physical properties of calcium alginate

\begin{tabular}{lll}
\hline Fluid & Calcium Alginate & Milk \\
\hline Density & $2117.3 \mathrm{~kg} / \mathrm{m}^{3}$ & $1030 \mathrm{~kg} / \mathrm{m}^{3}$ \\
Molecular weight & 1170.93 & 18.01528 \\
Viscosity & - & 0.002127 \\
Diameter size & $300 \mu \mathrm{m}$ & - \\
\hline
\end{tabular}

In the boundary condition, impeller rotation speed was set up in rpm in z-axis and the simulation was run at three different speed as stated earlier. Time step size for all the design was specified as 0.05 for run of calculation for each computational design, different number of time step was specified as shown in Table 3. Maximum iteration for each time step was specified as 10 iteration/time step. The calculations were performed for all computational design and each of the design solutions converged after different time step for all of them.

Table 3

Number of iterations for different impeller

\begin{tabular}{llll}
\hline Impeller & Time Step Size(s) & Number of iterations & Time for impeller run \\
\hline T-shape & 0.05 & 600 & $30 \mathrm{~s}$ \\
Edge Beater Blade & 0.05 & 200 & $10 \mathrm{~s}$ \\
Paddle Blade & 0.05 & 420 & $21 \mathrm{~s}$ \\
5-Turbine Blade & 0.05 & 260 & $13 \mathrm{~s}$ \\
\hline
\end{tabular}




\subsection{Post-Processing}

This stage covers an important step which view/show the result analysis for the different shape and configuration of the impeller. Mixing of the fluid can be checked from the result of the volume fraction of milk and calcium alginate beads. The pressure drop should be low as possible for the good mixing and for high-efficiency impeller.

Contour plot was the function applicable in CFD-Post whereby it displayed the graphical results according to the data generated in Fluent. This function is significant because it allows the user to view the trend of the process happening in the domain and able to identify the exact location of the reaction happened during the simulation. In this study, the variables of contour plot that applied were velocity, pressure and volume fraction.

\section{Results}

Results from the contour plot were obtained and were compared among the four impeller (edge beater, T-shape, paddle and 5-turbine) at different speeds. Result of the calcium alginate distribution over the tank was also observed. Some validation was made with the experimental data.

\subsection{Comparison Between Different Impeller Flow Pattern}

Different impeller shows different flow for the calcium alginate bead which is important for the fluid mixing to identify the impeller flow pattern for the fluid. As can be observed from Figure 2 that the impeller pushes the fluid downwards producing one single loop in one direction that is along the axis of the miniature tank which is the indication for the axial flow pattern and single loop is due to the smaller gap between the impeller and bottom of the tank.

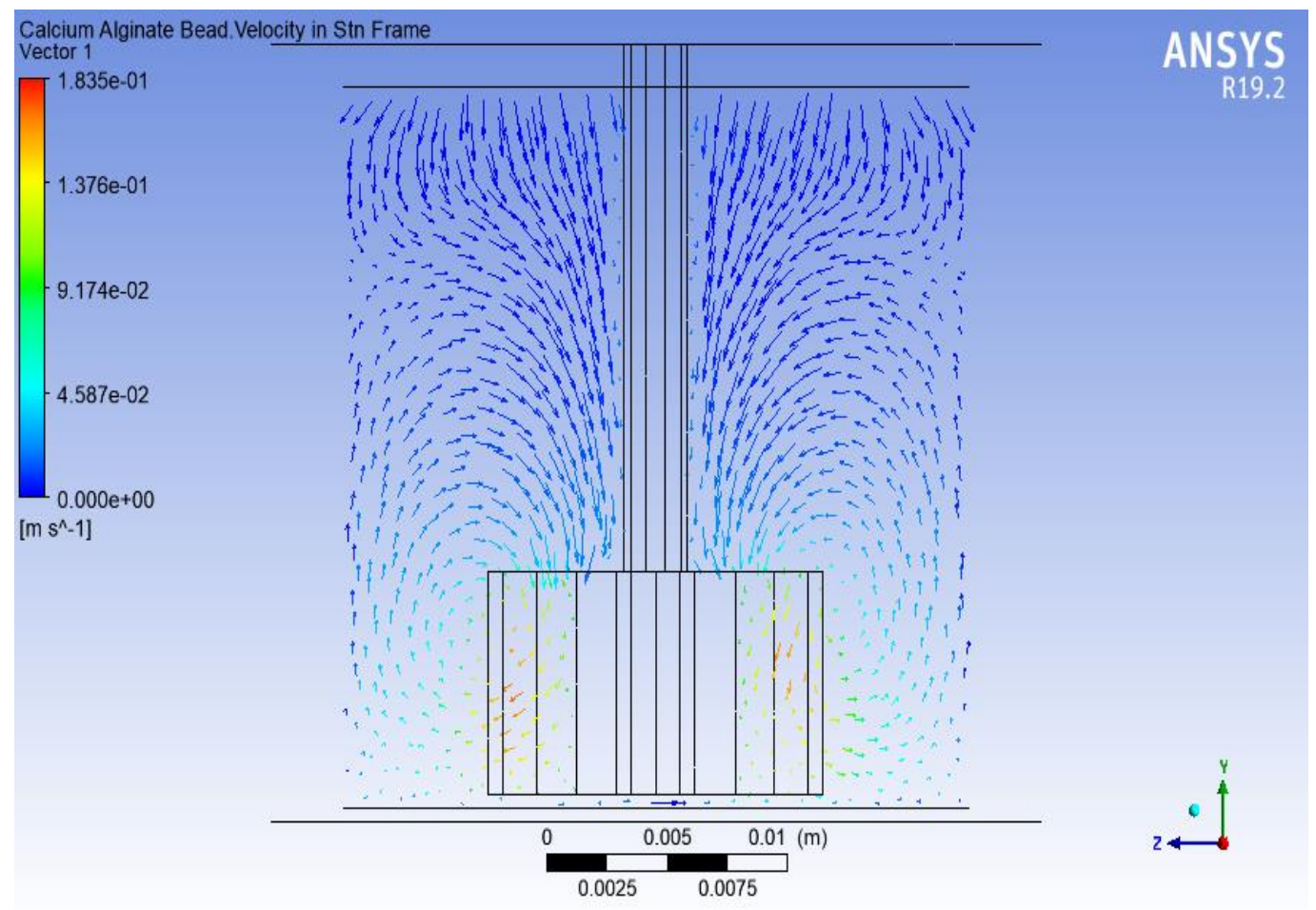

Fig. 2. Flow pattern for cross-section view of the 5 -Turbine blade at $250 \mathrm{rpm}$ 
In Figure 3 can be observed that the t-shape blade produces the same flow pattern as for 5turbine blade except it produces to two loops, it is also a radial impeller due to this flow pattern.

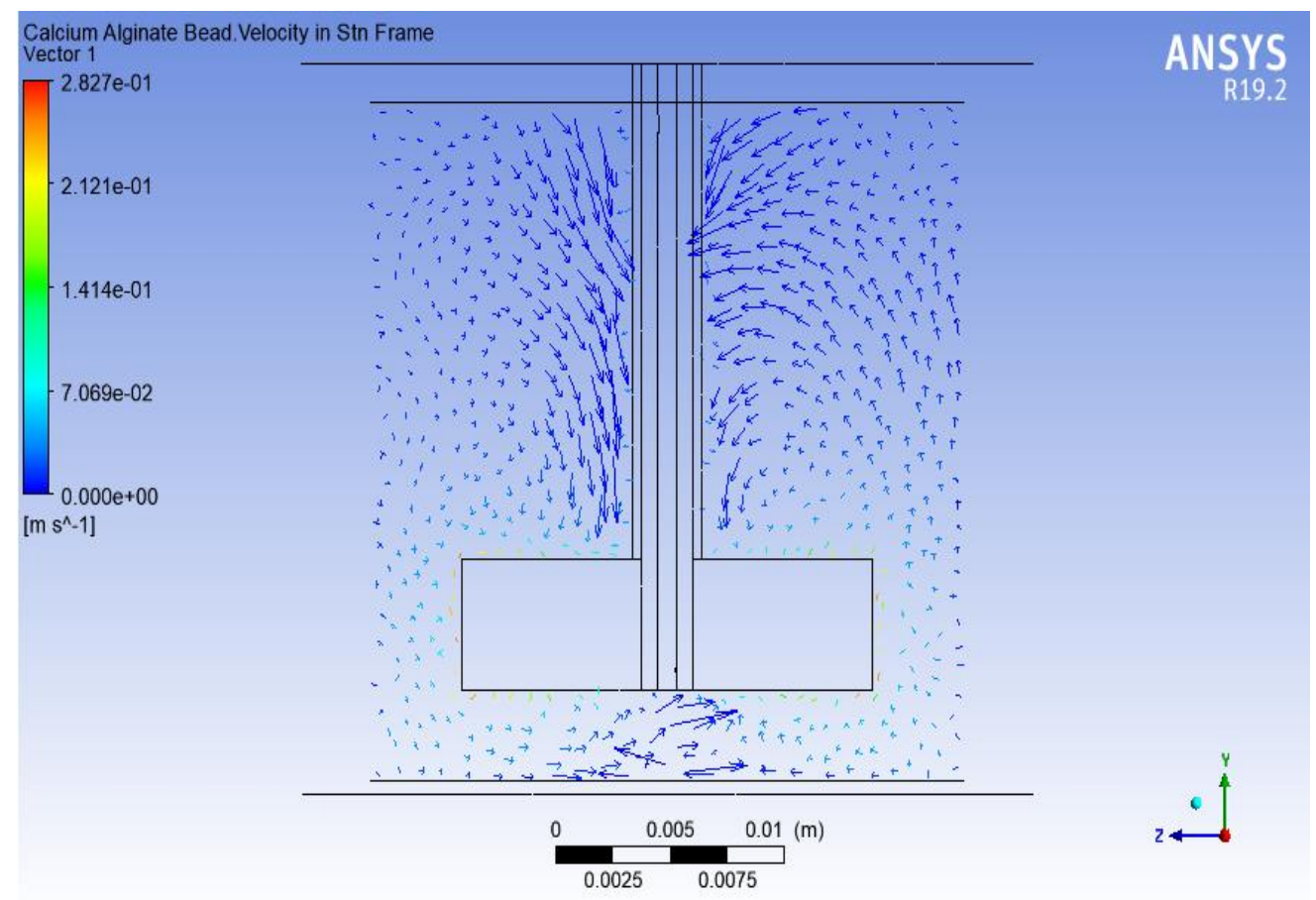

Fig. 3. Flow pattern for cross-section view of the 5 -Turbine blade at $250 \mathrm{rpm}$

Edge beater blade is a radial flow impeller because of its large diameter and long height and its cover 90-95\% of the tank diameter and are also known as clearance impeller [19] but in this study the diameter of impeller is $1.8 \mathrm{~cm}$ and the tank diameter is $3.2 \mathrm{~cm}$ so the ratio of impeller diameter to tank diameter is $59.4 \%$ which produces radial flow pattern, produces two loops flow pattern in opposite direction furthermore small rotational flow is produced as well in the between the impeller as it can be seen in Figure 4. So, can be concluded that this impeller flow pattern is mixed.

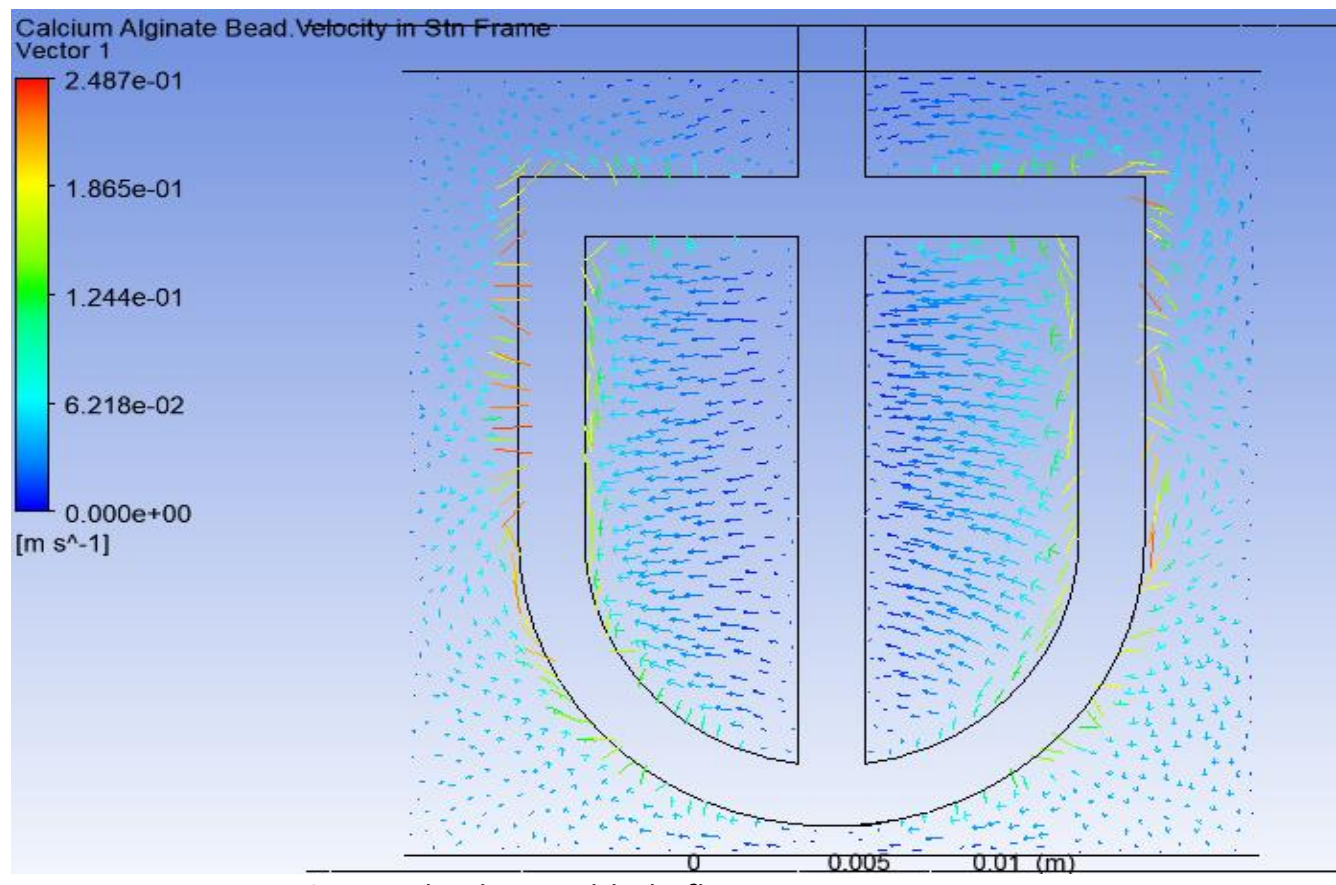

Fig. 4. Edge beater blade flow pattern at $250 \mathrm{rpm}$ 
Lastly for the last impeller in Figure 5 the flow could not able to recognize the impeller flow from the front view so had to analyze it from the top view, whether it is radial or axial or mixed impeller. In Figure 6 shows that the impeller makes axial flow as all the vector plane was placed in the centre of the blade make the arrow in same direction.

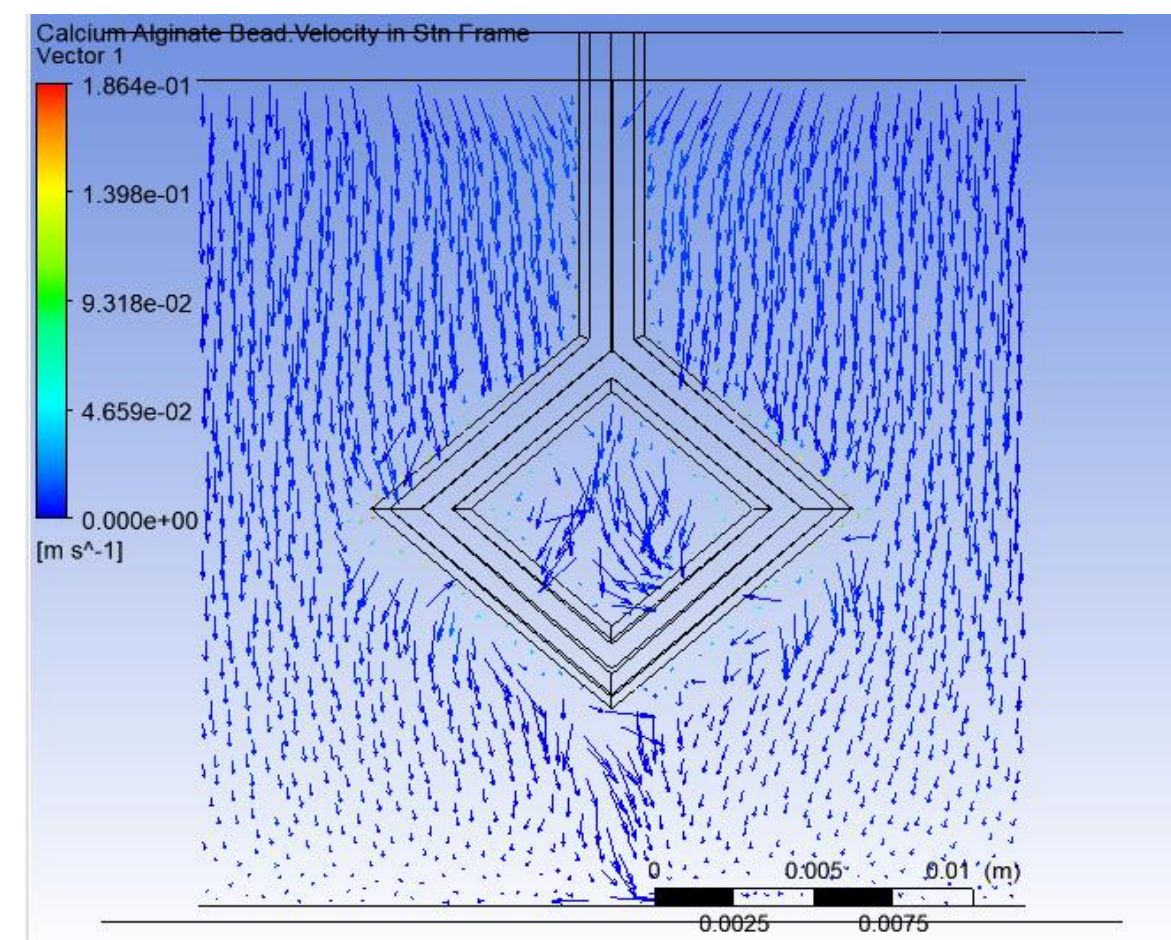

Fig. 5. Front view for paddle blade impeller flow pattern at $250 \mathrm{rpm}$

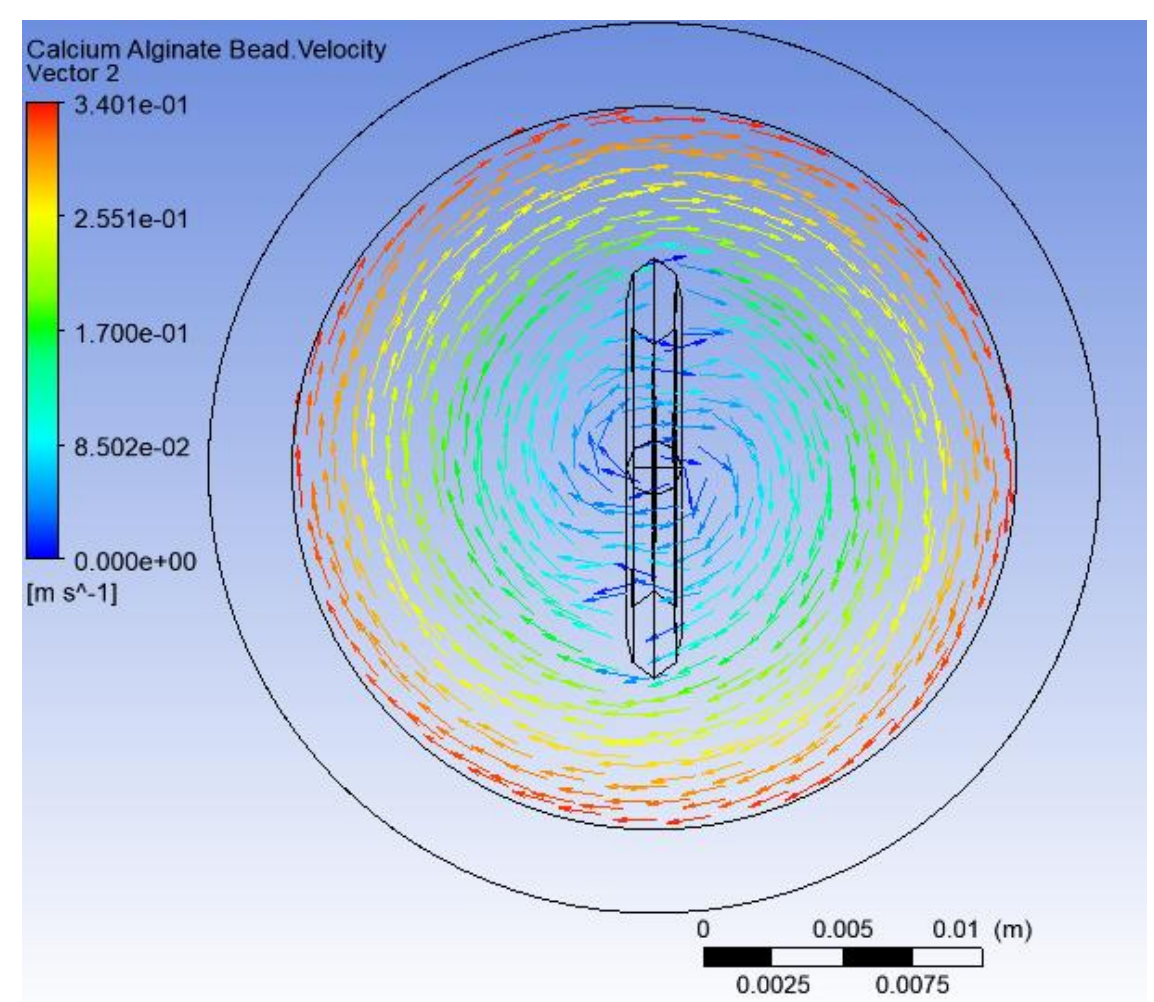

Fig. 6. Top mid-plane view for paddle blade impeller flow pattern at 250 rpm 


\subsection{Impeller Speed Effect on the Fluid}

The impeller speed rotation has great influence effect on the process of mixing as well as on the fluid motion. Subsequently, it also affects the efficiency of settling solid beads (calcium alginate) by the small change in the impeller speed of rotation. To achieve homogeneous mixing throughout the stirred vessel, the impeller must be run with optimum speed to accomplish the homogenous mixing and to avoid any vortex formation.

Figure 7 illustrates the volume fraction of the calcium alginate bead at 150, 250 and $300 \mathrm{rpm}$ for the paddle blade impeller. At z-axis mid plane, all the simulation was run according to the time frame that was initially set for the experiment for each impeller as mentioned in Table 3 . As it can see that for 150 and $250 \mathrm{rpm}$ there is only slightly changes and it is almost the same whereby for the $300 \mathrm{rpm}$ the beads are all over the tank which indicates that at $300 \mathrm{rpm}$ there is homogenous mixing which also indicates that $300 \mathrm{rpm}$ is optimum impeller rotation speed for homogeneous mixing.

As mentioned above that it makes axial pattern flow by the impeller which pushes the beads downwards in the centre this is the reason for the accumulation of the solid beads at the centre at $150 \mathrm{rpm}$ and $250 \mathrm{rpm}$. Zhang et al., [20] also reported the phenomena when studied the effect of impeller on behaviour of suspending particle materials in stirred tank.

In Figure 8 can be observed that all three speed produces a different result and the running time for this simulation was $10 \mathrm{~s}$. At impeller speed of $150 \mathrm{rpm}$ all the calcium alginate bead was half of the tank diameter without any formation of the vortex as it was mentioned earlier that such impeller is clearance impeller which means it will make radial flow pattern instead of axial flow.

At $250 \mathrm{rpm}$ a magnificent change can be observed for Figure 8. The axial flow produces two loops in opposite direction and the downward loop is more dominating which pushes the calcium alginate bead towards the bottom of the tank and also some fraction of beads is now above the impeller compared to the $150 \mathrm{rpm}$ speed of impeller. At $300 \mathrm{rpm}$ as compared to $250 \mathrm{rpm}$ most of the beads are at the bottom of the tank which indicates that vortex is formed. Vortex is undesired because some of the portions do not mix very well, reduces the contact portion of milk and beads at the above of the impeller less compared the 250rpm.

T-shape simulation was run for $30 \mathrm{~s}$, as this blade also makes axial flow at $150 \mathrm{rpm} 75 \%$ of the tank is occupied with beads and this speed makes slightly vortex formation near to the shaft. As the speed is changed to 250rpm the axial flow pattern becomes bigger and the volume fraction makes the vortex formation more the shaft.

At 300rpm the beads are distributed throughout the tank is can be observed through the Figure 9. No vortex formation of the calcium alginate beads can be observed at this speed. Figure 10 shows that at $250 \mathrm{rpm}$ and 300rpm it shows almost the same result which means increasing 50rpm of the speed of the impeller there will not show significant effect on the distribution of the beads whereby compared to $150 \mathrm{rpm}$ it is a massive change in the volume fraction of the beads. At $150 \mathrm{rpm}$ there is a slight vortex formation near to the shaft of the impeller, this simulation was run $13 \mathrm{~s}$ for all the speed. 


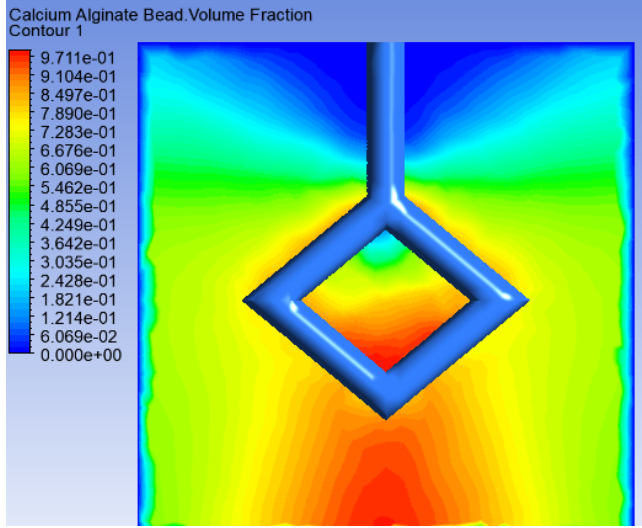

(a)

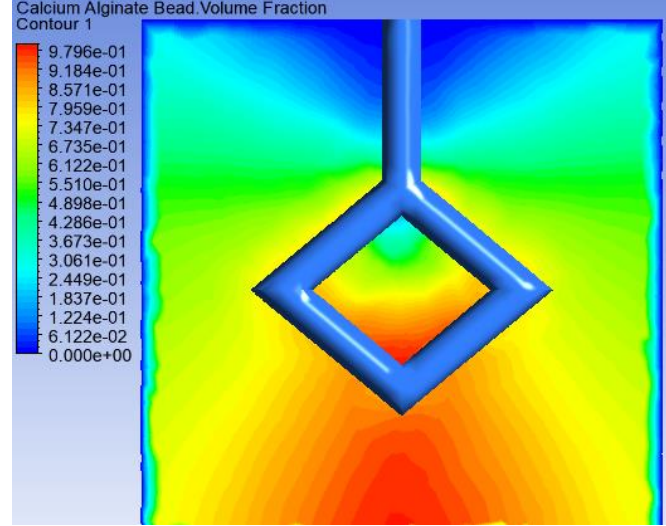

(b)

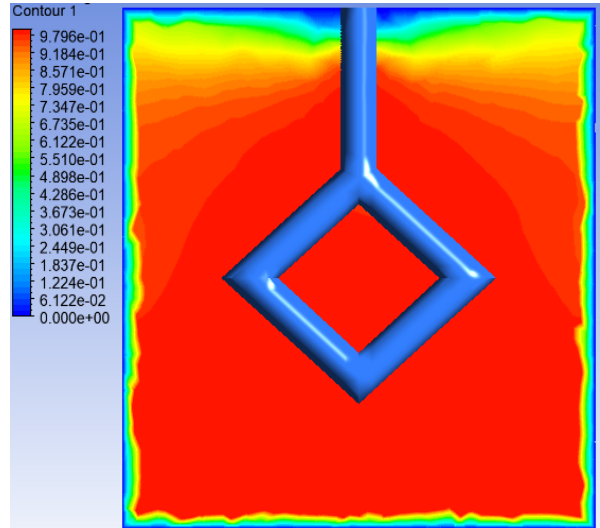

(c)

Fig. 7. Volume fraction of calcium alginate bead at mid-plane for the paddle blade impeller a) $150 \mathrm{rpm} \mathrm{b)} 250 \mathrm{rpm}$ c) $300 \mathrm{rpm}$

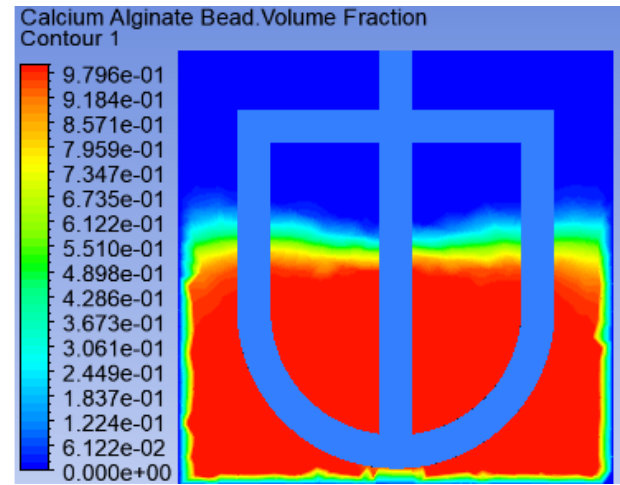

(a)

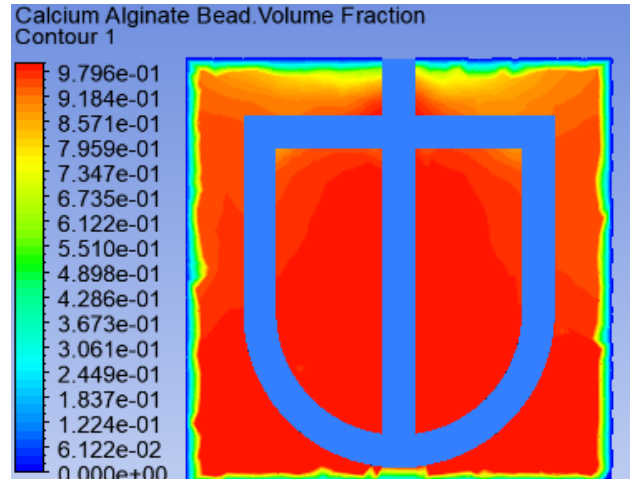

(b)

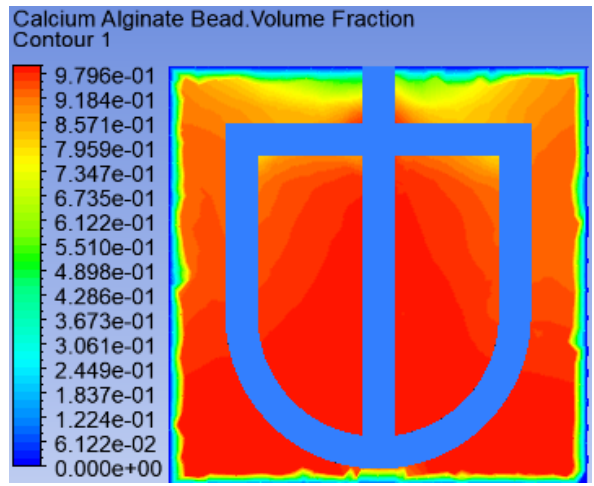

(c)

Fig. 8. Volume fraction of calcium alginate bead at mid-plane for the Edge Beater blade impeller a) $150 \mathrm{rpm} \mathrm{b}) 250 \mathrm{rpm} \mathrm{c)} 300 \mathrm{rpm}$ 


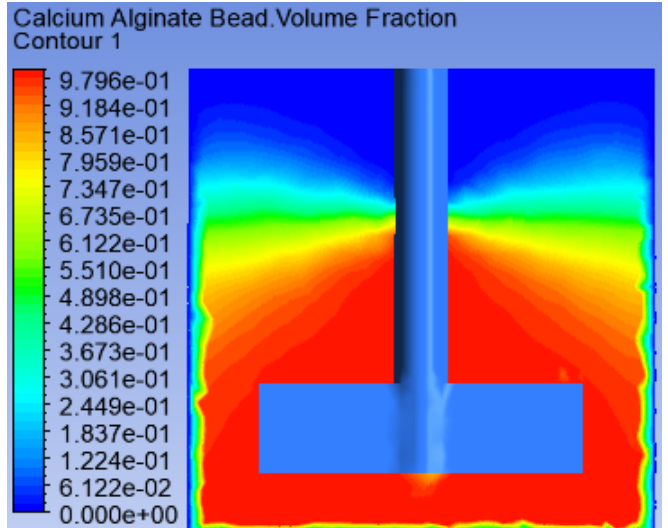

(a)

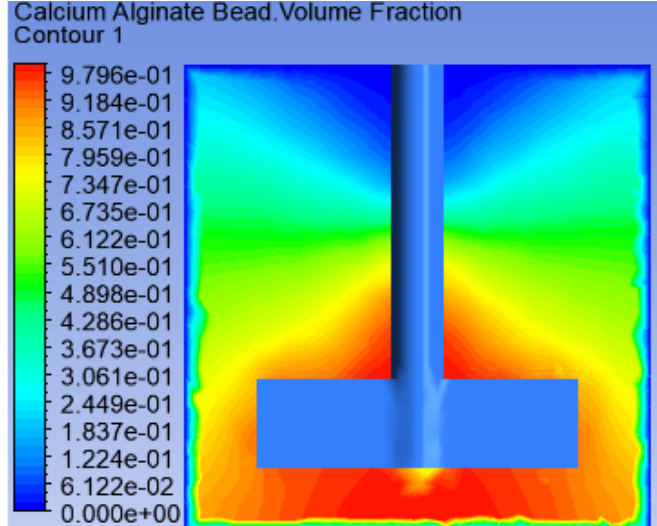

(b)

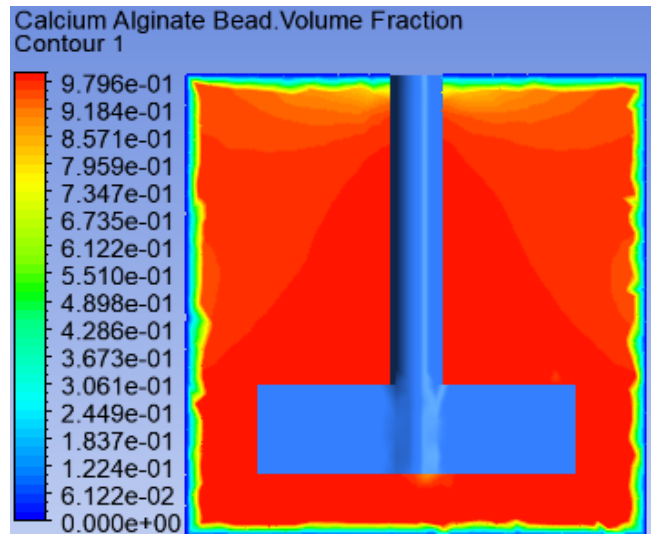

(c)

Fig. 9. Volume fraction of calcium alginate bead at mid-plane for the T-shape blade impeller a) $150 \mathrm{rpm} \mathrm{b)} 250 \mathrm{rpm}$ c) $300 \mathrm{rpm}$

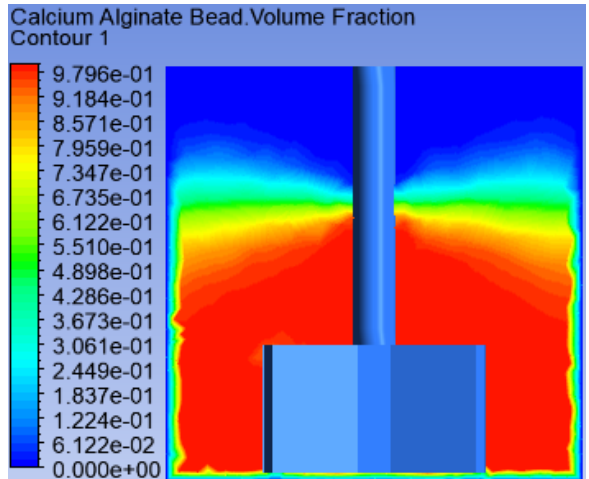

(a)

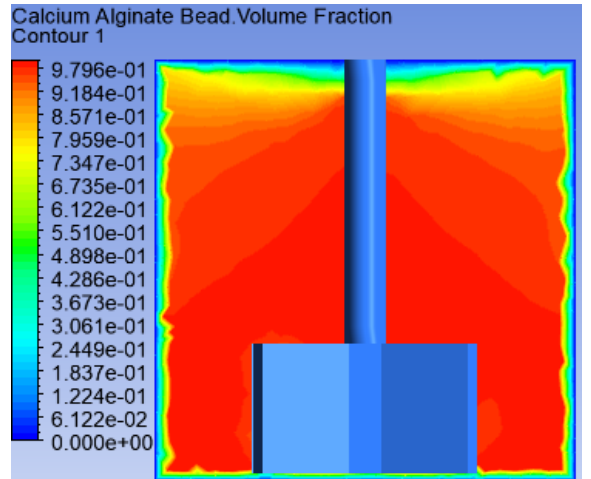

(b)

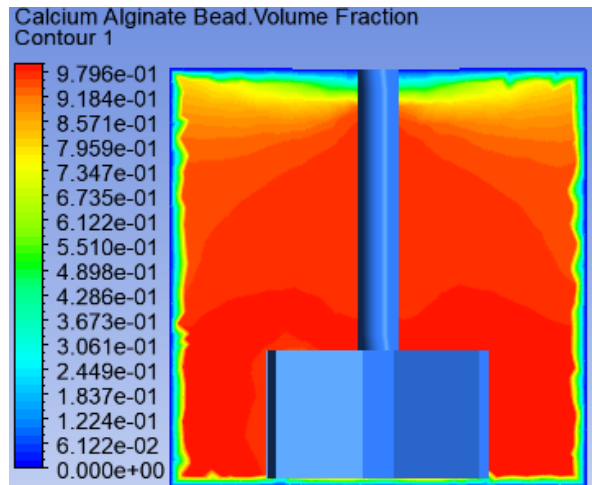

(c)

Fig. 10. Volume fraction of calcium alginate bead at mid-plane for the 5-turbine blade impeller a) $150 \mathrm{rpm} \mathrm{b)} 250 \mathrm{rpm}$ c) $300 \mathrm{rpm}$ 
It was quite hard to do a comparison between the impeller as each impeller was run for a different period and even the distance from the bottom of the vessel wasn't consistent. Table 4 shows the time for each impeller to run and the formation of the vortex. And the summary of all the impeller data.

\section{Table 4}

Comparison between experimental and simulation result

\begin{tabular}{lllll}
\hline Impeller Type & $\begin{array}{l}\text { Impeller rotation speed } \\
(\mathrm{rpm})\end{array}$ & $\begin{array}{l}\text { Simulation time } \\
(\mathrm{s})\end{array}$ & $\begin{array}{l}\text { Vortex Formation } \\
\text { (Simulation) }\end{array}$ & $\begin{array}{l}\text { Vortex Formation } \\
\text { (Experimental) }\end{array}$ \\
\hline T-shape blade & 150 & 30 & No & No \\
& 250 & 30 & No & No \\
Paddle blade & 300 & 30 & No & No \\
& 150 & 21 & No & No \\
5-Turbine blade & 250 & 21 & No & No \\
& 300 & 21 & No & No \\
Edge-Beater & 150 & 13 & No & No \\
Blade & 250 & 13 & Yes & No \\
& 250 & 13 & No & Yes \\
\hline
\end{tabular}

As the result was compared with the experimental and simulation data of the vortex, it can be observed from the data that T-shape blade, paddle blade and 5-turbine blade shows that there was no formation of the vortex whereby for the edge beater blade result for simulation shows that there was vortex formation at $300 \mathrm{rpm}$ only and for the experimental at 250 and $300 \mathrm{rpm}$ which makes a little conflict. Edge beater blade took $10 \mathrm{~s}$ for the distribution the calcium alginate beads over the tank at $250 \mathrm{rpm}$ compared to the others and the times the impeller was run in the tank was even lesser than the other impeller. It can also conclude that the impeller which produces mixed flow pattern is better for the mixing of two-phase fluid mixing.

\section{Conclusions}

It can be concluded that the edge beater blade took $10 \mathrm{~s}$ to distribute the calcium alginate beads over the tank at $250 \mathrm{rpm}$ compared to the others and the times the impeller was run in the tank was even lesser than the other impeller. It can also conclude that the impeller which produces mixed flow pattern is better for the mixing of two-phase fluid mixing. In this study, the position of the impeller wasn't kept constant from the bottom of the tank and the time to run each of the design wasn't the same so it was quite hard to compare between the impeller effectiveness in mixing. This study was a continuous study for the researched done by Muttablib [16].

\section{Acknowledgement}

The authors gratefully acknowledge the financial support from Centre of Excellence for Research, Value Innovative and Entrepreneurship (CERVIE), UCSI University Proj-In-FETBE-056.

\section{References}

[1] Hosseini, Seyed, Dineshkumar Patel, Farhad Ein-Mozaffari, and Mehrab Mehrvar. "Study of solid- liquid mixing in agitated tanks through computational fluid dynamics modeling." Industrial \& Engineering Chemistry Research 49, no. 9 (2010): 4426-4435. https://doi.org/10.1021/ie901130z 
[2] Kasat, G. R., A. R. Khopkar, V. V. Ranade, and A. B. Pandit. "CFD simulation of liquid-phase mixing in solid-liquid stirred reactor." Chemical Engineering Science 63, no. 15 (2008): 3877-3885.

https://doi.org/10.1016/i.ces.2008.04.018

[3] Paul, Edward L., Victor A. Atiemo-Obeng, and Suzanne M. Kresta, eds. Handbook of industrial mixing: science and practice. John Wiley \& Sons, 2004.

https://doi.org/10.1002/0471451452

[4] Ascanio, Gabriel. "Mixing time in stirred vessels: A review of experimental techniques." Chinese Journal of Chemical Engineering 23, no. 7 (2015): 1065-1076.

https://doi.org/10.1016/i.cjche.2014.10.022

[5] Tamburini, A., A. Cipollina, Gdm Micale, A. Brucato, and M. Ciofalo. "CFD simulations of dense solid-liquid suspensions in baffled stirred tanks: Prediction of suspension curves." Chemical Engineering Journal 178 (2011): 324-341. https://doi.org/10.1016/i.cej.2011.10.016

[6] Isa, N. M., RA Mohamad Rushdi, A. Sadikin, S. M. Basharie, M. Universiti, and T. Hussein. "Investigation of the Fluid Motion with Various Clearances in Biodiesel Reactor by Using CFD." Journal of Advanced Research Design 10, no. 1 (2015): 1-8.

[7] Tamburini, A., A. Cipollina, Gdm Micale, A. Brucato, and M. Ciofalo. "CFD simulations of dense solid-liquid suspensions in baffled stirred tanks: Prediction of suspension curves." Chemical Engineering Journal 178 (2011): 324-341. https://doi.org/10.1016/i.cej.2011.10.016

[8] Sinaga, Nazaruddin, Kurnia Hatta, Nurjehan Ezzatul Ahmad, and Maizirwan Mel. "Effect of rushton impeller speed on biogas production in anaerobic digestion of continuous stirred bioreactor." Journal of Advanced Research in Biofuel and Bioenergy 3, no. 1 (2018): 9-18.

[9] Gradov, Dmitry. "Experimentally validated numerical modelling of reacting multiphase flows in stirred tank reactors." PhD diss. Lappeenranta-Lahti University of Technology LUT (2019).

[10] Priyadi, K., Chin-Tu Lu, and H. Sutanto. "Optimization of impeller design for stirred tank using computational fluid dynamics." In IOP Conference Series: Materials Science and Engineering, vol. 567, no. 1, p. 012032. IOP Publishing, 2019.

https://doi.org/10.1088/1757-899X/567/1/012032

[11] Paul, Edward L., Victor A. Atiemo-Obeng, and Suzanne M. Kresta, eds. Handbook of industrial mixing: science and practice. John Wiley \& Sons, 2004.

https://doi.org/10.1002/0471451452

[12] Micheletti, M., and M. Yianneskis. "Study of fluid velocity characteristics in stirred solid-liquid suspensions with a refractive index matching technique." Proceedings of the Institution of Mechanical Engineers, Part E: Journal of Process Mechanical Engineering 218, no. 4 (2004): 191-204.

https://doi.org/10.1243/0954408042466945

[13] Montante, Giuseppina, Alessandro Paglianti, and Franco Magelli. "Analysis of dilute solid-liquid suspensions in turbulent stirred tanks." Chemical Engineering Research and Design 90, no. 10 (2012): 1448-1456.

https://doi.org/10.1016/j.cherd.2012.01.009

[14] Unadkat, Heema, Chris D. Rielly, Graham K. Hargrave, and Zoltan K. Nagy. "Application of fluorescent PIV and digital image analysis to measure turbulence properties of solid-liquid stirred suspensions." Chemical Engineering Research and Design 87, no. 4 (2009): 573-586.

https://doi.org/10.1016/i.cherd.2008.11.011

[15] J.Y. Luo, A.D. Gosman, and R.I. Issa. "Prediction of impeller induced flows in mixing vessels using multiple frames of reference." Inst. Chem. Eng. Symp. Ser. 136 (1994): 549-556.

[16] Muttalib. "Design and performance of millilitre range bioreactor prototype for bioprocess operation." PhD diss. University Teknologi Malaysia (2019)

[17] Santos-Moreau, Vania, Lena Brunet-Errard, and Matthieu Rolland. "Numerical CFD simulation of a batch stirred tank reactor with stationary catalytic basket." Chemical engineering journal 207 (2012): 596-606. https://doi.org/10.1016/i.cej.2012.07.020

[18] Huang, Weidong, and Kun Li. "CFD simulation of flows in stirred tank reactors through prediction of momentum source." Nuclear Reactor Thermal Hydraulics and Other Applications (2013): 135-153.

https://doi.org/10.5772/51754

[19] Tekchandaney, J. "Mixing Expert." 2019.

[20] Zhang, Yulong, Zhengming Gao, Zhipeng Li, and J. J. Derksen. "Transitional flow in a Rushton turbine stirred tank." AlChE Journal 63, no. 8 (2017): 3610-3623.

https://doi.org/10.1002/aic.15809 